\title{
Internal medicine residents' perspectives and practice about do not resuscitate orders: survey analysis in the western region of Saudi Arabia
}

This article was published in the following Dove Press journal:

Advances in Medical Education and Practice

26 May 2015

Number of times this article has been viewed

\section{Ahmed Aljohaney \\ Yasser Bawazir}

Department of Medicine, Faculty of Medicine, King Abdulaziz University, Jeddah, Saudi Arabia
Correspondence: Ahmed Aljohaney Department of Medicine, Faculty of Medicine, King Abdulaziz University, PO Box 80215, Jeddah 21589, Saudi Arabia

Tel +966126401000 ext 22319

Fax +966126408315

Email drajohani@yahoo.com
Background: The purpose of this study was to analyze the perceptions and practices of internal medicine residents in the western region of Saudi Arabia regarding the implementation of do not resuscitate (DNR) orders to improve future training practices among physicians.

Methods: Medical residents involved in training programs in the western region of Saudi Arabia, including Jeddah, Makah, Medinah, and Taif, were invited to participate in a cross-sectional, anonymous, online survey regarding DNR orders. The 16-question survey was distributed to residents in all training programs in the region using surveymonkey.com, and the results were collected and tabulated.

Results: Of 364 residents, 157 completed the questionnaire, resulting in a 43\% response rate. The study showed that most (66\%) internal medicine residents in the western region of Saudi Arabia participate in DNR discussions with patients and family or surrogate decision-makers. In addition, $43 \%$ were observed by faculty members, and half of them (51.9\%) reported feeling comfortable during these discussions. Furthermore, most residents believed that additional educational programs would enhance their competence in addressing issues related to DNR discussions.

Conclusion: This study highlights the need for a structured curriculum to teach skills relating to end-of-life issues such as DNR orders to residents in the Saudi Arabian medical system. The majority of residents surveyed believe they would benefit from additional training in DNR discussions. Therefore, an evidence-based curriculum providing instruction for improving discussions regarding DNR orders would improve physician confidence and effectiveness in caring for critically ill patients.

Keywords: medical residents, do not resuscitate, internal medicine training program, Saudi Arabia

\section{Introduction}

Instructing medical residents in the appropriate use of do not resuscitate (DNR) orders is perhaps one of the most difficult aspects of clinical training. Social differences have necessitated variations in models of communication between doctors and patients, including methods for discussing and implementing DNR orders. ${ }^{1}$ This type of communication is exceedingly important in cases of end-stage disease, such as advanced malignancy or multiple organ failure. However, the controversial nature of DNR orders often leads to inadequate physician training on the topic, which may impact the perceptions and practices of medical residents. Most emergency room physicians initiate cardiopulmonary resuscitation regardless of the expected outcome because of concerns about litigation or criticism rather than their professional opinion. ${ }^{2}$ This highlights the 
importance of continuing education on the topic of DNR practices. In fact, $90 \%$ of surveyed US medical residents felt they would benefit from formal training in practices related to DNR orders. ${ }^{3}$

Saudi Arabia is a religious and traditional country for the most part. ${ }^{1}$ Most hospitals in Saudi Arabia have adopted a DNR policy and practice that is compatible with the Fatwa. ${ }^{4,5}$ Fatwa in the Islamic religion is a ruling on a point of Islamic law given by a recognized authority. The Fatwa opinion on DNR was issued in $1988 .{ }^{5}$ It states that: "If three knowledgeable and trustworthy physicians agree that the patient's condition is hopeless, life-supporting machines can be withheld or withdrawn. The family members' opinion is not included in decision-making as they are unqualified to make such decisions". ${ }^{5}$ However, the reason behind the DNR decision must be clearly documented, and it must be explained to and understood by the patient and/or the most appropriate responsible family member. ${ }^{4,5}$

Recent decades have brought about significant changes in the lifestyle of many citizens within Saudi Arabia because the country has shifted from being primarily nomadic to a more urbanized society. ${ }^{6}$ This change corresponds to a rise in modern medical facilities and technology; however, increasing patient discontent has resulted in a surge of malpractice suits and medical litigation. ${ }^{7}$ Nonetheless, as a result of the ethical and moral aspects involved in DNR orders, the role and training of the attending physician is of critical importance. Therefore, the purpose of this study was to analyze the perceptions and practices of internal medicine residents in the implementation of DNR orders to improve future training practices among physicians in Saudi Arabia.

\section{Materials and methods}

\section{Selection and description of participants}

Medical residents involved in training programs in the western region of Saudi Arabia, including Jeddah, Makah, Medinah, and Taif, were invited to participate in a crosssectional, anonymous, online survey regarding DNR orders. No other exclusion criteria were implemented. The survey was disseminated using the http://www.surveymonkey.com online survey program.

\section{Technical information}

The questionnaire was disseminated in April 2013 to medical residents who had begun training no later than the beginning of the 2012 academic year, which started in October. This ensured that first-year residents would have received inpatient exposure for at least half of the academic year prior to participating in the study. The questionnaire used was taken from a previously published manuscript, with slight modifications. ${ }^{3}$ It consisted of 16 questions and was sent to nine medical centers in the western region of Saudi Arabia. There were 364 residents, of whom 197 (54\%) were male, enrolled in the participating training programs in the region. A second request to complete the survey was sent 8 weeks after the initial attempt to enhance the response rate. Participants were assured of the confidentiality of their responses and that all findings would be used solely for research purposes. No incentive was provided for their contribution. Permission to conduct this study was granted by the biomedical ethics research committee of King Abdulaziz University.

\section{Statistical analysis}

We used Statistical Package for the Social Sciences version 20 software (IBM Corporation, Armonk, NY, USA) for the statistical analysis. Descriptive statistics were used to show the mean, range, variation, counts, and percentages for demographics and the majority of the remaining variables, whether continuous or categorical variables. A chi-square test was used for establishing the relationship between categorical variables. A conventional $P$-value less than 0.05 was used to reject the null hypothesis.

\section{Results}

The final response rate for residents across all participating medical programs was $43 \%$; 131 surveys were completed after the initial dissemination and an additional 26 were completed following the second attempt. Participants completed the survey within 5 minutes on average. Residents of both sexes completed the survey; 105 (70\%) were male (Table 1). The male to female ratio of the respondents was $2.3: 1$, while the male to female ratio of the total residents in all programs was $1.2: 1$. The mean age of the residents was $28.3 \pm 2.4$ years. The residents were distributed across the residency levels: 44 (30.6\%) were in R1, 32 (22.2\%) were in R2, 26 (18.1\%) were in R3, and 42 (29.2\%) were in R4.

Sixty-six percent of participating residents indicated previous participation in a DNR discussion with a patient, family, and/or surrogate decision-maker, which lasted 6-10 minutes in nearly one-third (30.8\%) of residents surveyed. Many of the participants $(37.8 \%)$ had discussed the topic of DNR 1-3 times. Of those who participated in a DNR discussion, $60.3 \%$ initiated the conversation by asking the family about their overall understanding of the patient's illness. An additional $26 \%$ of participants elected to discuss the patient's 
Table I Study demographics*

\begin{tabular}{lll}
\hline & $\mathbf{n = 1 5 7}$ & $\%$ \\
\hline Sex & 45 & 30.0 \\
Female & 105 & 70.0 \\
Male & & \\
City & 86 & 57.3 \\
Jeddah & 24 & 16.0 \\
Makkah & 17 & 11.3 \\
Medinah & 23 & 15.3 \\
Taif & & \\
Residency level & 44 & 30.6 \\
RI & 32 & 22.2 \\
R2 & 26 & 18.1 \\
R3 & 42 & 29.2 \\
R4 & Mean & SD \\
\hline Age, years & & \\
Minimum 25 & 28.33 & 2.455 \\
Maximum 38 & & \\
\hline
\end{tabular}

Note: ${ }^{*} \mathrm{n}$ changes per variable due to missing values.

Abbreviation: SD, standard deviation.

medical problems when addressing the DNR topic. Eight (5.1\%) discussed the DNR status in an outpatient setting.

During DNR discussions, the comfort levels of the survey respondents varied. Half (51.9\%) reported they were comfortable (very comfortable or somewhat comfortable) conducting DNR discussions. Additionally, 57\% reported a lack of supervision by faculty members or senior residents when discussing DNR. Nevertheless, 68\% had previously observed a faculty member discussing DNR with patients. The most common limitation to meaningful DNR discussions was a lack of understanding on the part of the patient, the patient's family, or surrogate followed by inadequate training. A small proportion (12.9\%) of participants felt it was not their job to engage in DNR discussions, and time restrictions were a barrier for only $3.2 \%$ of them (Table 2 ).

Patient status also affected the likelihood that DNR discussions would occur. Only $13.4 \%$ of survey respondents discussed DNR status with each patient admitted. In addition, 39\% reported readdressing the DNR status when they assumed care for new patients from a colleague. A significant majority (77\%) believed they would benefit from formal training in DNR during their residency program (Table 3), while only $33 \%$ had received any actual training (Table 4 ).

The residency level of the participants did not significantly affect their reported comfort level with DNR discussions $(P=0.33)$. Fourth-year residents represented $36.1 \%$ of the total number of respondents who felt comfortable discussing DNR with patients (Table 5); however, the number who reported familiarity with the DNR form in their hospitals
Table 2 Survey questions addressing DNR discussions and resident responses*

\begin{tabular}{|c|c|c|}
\hline & & $\%$ \\
\hline \multicolumn{3}{|c|}{$\begin{array}{l}\text { How many times have you discussed DNR status with a patient and/or } \\
\text { family/surrogate? }\end{array}$} \\
\hline 0 & 53 & 34.0 \\
\hline $\mathrm{I}-3$ & 59 & 37.8 \\
\hline $4-8$ & 24 & 15.4 \\
\hline$>9$ & 20 & 12.8 \\
\hline
\end{tabular}

How many times have you discussed DNR status with patient or family in the outpatient setting?

0

$1-5$

$6-10$

$148 \quad 94.9$

$6-10$

$5 \quad 3.2$

$2 \quad 13$

How do you open a discussion about DNR with the patient/family/ surrogate?

Ask about their understanding of the patient's illness $88 \quad 60.3$

$\begin{array}{llll}\text { Explain what DNR is } & 15 & 10.3\end{array}$

Ask if they know what DNR is $\quad 5 \quad 3.4$

Discuss the patient's medical problems $\quad 38 \quad 26.0$

On average, how much time do you spend in discussing DNR status

with patient and/or family/surrogate?

$\begin{array}{lll}0-5 \text { minutes } & 24 & 15.4 \\ 6-10 \text { minutes } & 48 & 30.8 \\ >10 \text { minutes } & 44 & 28.2 \\ \text { Not done before } & 40 & 25.6\end{array}$

How comfortable are you in discussing DNR status with patient and/or family/surrogate?

$\begin{array}{lll}\text { Not comfortable } & 73 & 48.0 \\ \text { Somewhat comfortable } & 61 & 40.1 \\ \text { Very comfortable } & 18 & 11.8\end{array}$

Who has observed you while discussing DNR status with patient and/or family/surrogate?

$\begin{array}{lll}\text { Faculty member } & 27 & 17.9\end{array}$

$\begin{array}{lll}\text { Senior resident } & 38 & 25.2\end{array}$

$\begin{array}{lll}\text { No one } & 86 & 57.0\end{array}$

What are the possible barriers to your effective DNR discussions with patient and/or family/surrogate?

Lack of time $\quad 5 \quad 3.2$

Inadequate training $\quad 34 \quad 21.9$

Lack of patient or family understanding $\quad 82 \quad 52.9$

$\begin{array}{lll}\text { This is not your job } & 20 & 12.9\end{array}$

$\begin{array}{lll}\text { Other } & 14 & 9.0\end{array}$

Note: $*_{n}$ changes per variable due to missing values.

Abbreviation: DNR, do not resuscitate.

was not significant when compared with less experienced residents $(33.8 \% ; P=0.056)$. In contrast, first-year residents represented the majority of respondents (38.3\%) who had received a formal education about DNR; however, the difference was not statistically significant $(P=0.46)$.

\section{Discussion}

This study showed that most (66\%) internal medicine residents in the western region of Saudi Arabia participated in DNR discussions with patients and family or surrogate 
Table 3 Survey questions addressing role of DNR discussions during residency training*

\begin{tabular}{lll}
\hline & $\mathbf{n = 1 5 7}$ & $\%$ \\
\hline $\begin{array}{l}\text { Do you discuss DNR status with patient or the } \\
\text { family on each new hospital admission? }\end{array}$ & 21 & 13.4 \\
$\begin{array}{l}\text { Do you discuss DNR status with patients in the } \\
\text { outpatient setting? }\end{array}$ & 6 & 3.9 \\
$\begin{array}{l}\text { Have you observed a faculty member discussing } \\
\text { DNR status with patient and/or family/surrogate? }\end{array}$ & 103 & 68.2 \\
$\begin{array}{l}\text { Do you think training during residency will help } \\
\text { you to improve your ability to discuss DNR }\end{array}$ & 120 & 76.9 \\
$\begin{array}{l}\text { status with patient and/or family/surrogate? } \\
\begin{array}{l}\text { Do you readdress the patient's DNR status with } \\
\text { patient and/or family/surrogate when you assume } \\
\text { care from a colleague/admitting team? }\end{array}\end{array}$ & 58 & 39.2 \\
$\begin{array}{l}\text { Are you familiar with the DNR form used at } \\
\text { your institution? }\end{array}$ & 121 & 78.1
\end{tabular}

Note: $*_{n}$ changes per variable due to missing values.

Abbreviation: DNR, do not resuscitate.

decision-makers, whereas in a similar US study, $78 \%$ of residents participated in such discussions. ${ }^{3}$ We found that $43 \%$ of these discussions were observed by faculty members, whereas $26 \%$ were observed in the other study. ${ }^{3}$ The lack of supervision by senior staff members in most of these discussions may raise concerns about their quality. As in the US study, most of our participants indicated that they initiated DNR discussions by asking the families about their overall understanding of the illness and very few residents felt it was not their job to discuss DNR orders. ${ }^{3}$

Compared with other medical discussions, the comfort level and confidence in discussing DNR was reportedly low among physicians and house staff. ${ }^{8}$ Similarly, internal medicine residents in Saudi Arabia experienced difficulties with these discussions in particular. ${ }^{3,8}$ However, we noted a few differences. More than half of the residents (51.9\%) we surveyed were comfortable with the topic, which is greater than that reported elsewhere. ${ }^{3,8}$ The higher comfort level

Table 4 Questions addressing formal DNR training*

\begin{tabular}{lll}
\hline & $\mathbf{n = 1 5 7}$ & $\%$ \\
\hline $\begin{array}{l}\text { Have you ever had a formal lecture or other didactic session on } \\
\text { obtaining DNR orders? }\end{array}$ & $5 \mathrm{I}$ & 32.5 \\
Yes & 106 & 67.5 \\
No & $\mathbf{n = 5 I}$ & $\%$ \\
\hline & & \\
If you answered yes to the above question, where? & 23 & 15.8 \\
Medical school & 20 & 13.7 \\
Residency training & 3 & 2.1 \\
Symposia & 5 & 3.4 \\
\hline Other
\end{tabular}

Note: ${ }^{*}$ changes per variable due to missing values.

Abbreviation: DNR, do not resuscitate.
Table 5 Survey results addressing resident training and comfort levels stratified by residency year*

\begin{tabular}{|c|c|c|c|c|c|}
\hline \multirow[t]{2}{*}{ Domains } & \multicolumn{4}{|c|}{ Residency } & \multirow[t]{2}{*}{$P$-value } \\
\hline & RI $n=44$ & $\mathbf{R} 2 \mathrm{n}=32$ & $\mathbf{R} 3 \mathrm{n}=\mathbf{2 6}$ & $R 4 n=42$ & \\
\hline \multicolumn{6}{|c|}{$\begin{array}{l}\text { How comfortable are you in discussing DNR status with patient and/or } \\
\text { family/surrogate? }\end{array}$} \\
\hline $\begin{array}{l}\text { Not } \\
\text { comfortable }\end{array}$ & $24(54 \%)$ & $15(47 \%)$ & $13(50 \%)$ & $16(38 \%)$ & 0.332 \\
\hline Comfortable & 18 (4I\%) & 17 (53\%) & II (42\%) & $26(62 \%)$ & \\
\hline \multicolumn{6}{|c|}{$\begin{array}{l}\text { Have you ever had a formal lecture or other didactic session on } \\
\text { obtaining DNR orders? }\end{array}$} \\
\hline Yes & $18(4 \mid \%)$ & II (34\%) & $7(27 \%)$ & II (26\%) & 0.459 \\
\hline No & $26(59 \%)$ & $21(66 \%)$ & $19(73 \%)$ & $31(74 \%)$ & \\
\hline \multicolumn{6}{|c|}{ Are you familiar with the DNR form used at your institution? } \\
\hline Yes & $28(64 \%)$ & $26(81 \%)$ & 21 (81\%) & $37(88 \%)$ & 0.056 \\
\hline No & 15 (34\%) & $5(16 \%)$ & 5 (19\%) & $5(I 2 \%)$ & \\
\hline
\end{tabular}

Note: $*_{n}$ changes per variable due to missing values.

Abbreviation: DNR, do not resuscitate.

observed in our study may be explained by the higher percentage of residents who reported having been observed by an attending physician during DNR discussions compared with the US study (43\% versus 26\%). Interestingly, we did not find significant differences in the respondents' comfort levels addressing DNR across training levels. Therefore, this study does not support the assumption that senior residents are more comfortable addressing DNR orders than less experienced residents, despite having more clinical exposure. Furthermore, senior residents were not significantly more familiar with DNR forms in their institutions $(P=0.056)$. This finding supports the need for specific and focused education concerning the issue of DNR.

Nearly half of our participating residents reported discomfort to some degree in discussing DNR orders, although it is unknown whether this is because of the sensitive nature of the subject matter or a perceived lack of competence on the part of the resident. These results are similar to those reported elsewhere. ${ }^{3,9,10}$ Regardless, the level of comfort and confidence in discussing DNR orders could be greatly improved through formal training. In particular, a lack of understanding and misconceptions about the appropriateness of DNR discussions have been shown to be a significant barrier to productive interactions with patients and their families, as are time constraints and lack of comfort with the subject matter. ${ }^{11}$ Therefore, offering residents additional training in this area may provide the confidence required for improved patient/physician communication and trust. First-year residents in our study represented the majority of respondents who had received formal training on the issue of DNR (38.3\%). Residency programs should pay specific attention to improve residents' skills in DNR discussions, 
especially given the fact that most of our residents (77\%) expressed willingness and believed they would benefit from additional training in leading DNR discussions.

Local teaching efforts, targeted at improved documentation of DNR and cardiopulmonary resuscitation discussions, have been shown to result in significant improvements in both areas over the course of several weeks. ${ }^{12}$ In many institutions, medical students are taught communication skills through use of standardized patients. ${ }^{13}$ Similar results might be achieved for end-of-life care issues through development of workshops that incorporate use of standardized patients as part of a comprehensive training platform for residents who are faced with DNR issues. Ultimately, this would provide residents with a valuable resource and improve physician comfort levels and patient care.

Physician training toward improved DNR protocols must take into account the significant barriers associated with DNR orders in emergency and end-of-life medical practices. When physician-patient discussions fail to adequately address issues relating to DNR orders or other end-of-life issues, the results are often misunderstandings of patient preferences, and patients will often overestimate the benefits of life-sustaining treatments such as cardiopulmonary resuscitation. ${ }^{14}$ Research into the use of DNR orders as an effective clinical decision-making tool will enable physicians to confidently move toward more proactive care and improve policies regarding DNR orders. In particular, improvements to the DNR form, clear guidelines related to clinical decision-making, perceptions about how clinical care is affected, concern regarding "inappropriate" resuscitation, and discussions of DNR decisions may contribute to a better environment for residents and attending physicians to meet the needs of their patients. ${ }^{15}$

Physician education programs aimed toward the most promising interventions and decisions about overall treatment plans, including DNR orders, may include structured discussions along with formation of specialist teams to review information presented at the time of patient admission to the hospital. Overall, this may improve the clarity of the goals for clinical outcomes, aid communication among health care professionals, and reduce the risk of harm. In addition, standardized documentation has been shown to improve the frequency and quality of decisions surrounding DNR orders beyond simple patient and clinician education. ${ }^{16}$ In the USA, because physicians rarely choose to withhold resuscitation efforts unilaterally, it is increasingly important for the benefits and limitations of resuscitative efforts to be discussed with patients and/or their families or surrogates. ${ }^{17}$ This is also the practice in Saudi Arabia, where most physicians advocate a western model of disclosure and patient autonomy. ${ }^{1}$

The results presented in this study strengthen the argument for additional education and support in the use of DNR orders for physicians in Saudi Arabia. Furthermore, additional studies on the barriers unique to residents and physicians in Saudi Arabia would provide important insights into the most appropriate tools and training guidelines that should be implemented in medical training programs. For example, a review of physicians' and patients' views in Saudi Arabia versus the USA and Japan showed that patients prefer a family-centered model of care, despite recognition on the part of physicians of the importance of autonomy. ${ }^{1}$ Therefore, cultural distinctions may provide important guidelines for establishing the most effective training programs for medical residents in carrying out discussions involving DNR orders.

Our study has several limitations. First, it is based on self-report surveys, which may not always reflect accurate assessments or information. Second, participating residents were restricted to the western region of Saudi Arabia, which may not reflect views at a national level. Nonetheless, this study likely provides an accurate representation of the western region, because all the training centers within the area were represented in the study. Third, while the response rate was relatively low, it was reasonable and almost double that of a similar study conducted in the USA. ${ }^{3}$ However, the study does have strength in using a previously validated research tool. ${ }^{3}$ Furthermore, there was an equal distribution across training years R1-R4, allowing for assessment over the training period. By meeting these criteria, the study provides a good overview of the perceptions of internal medicine residents and their comfort levels discussing DNR status. In addition, the results report trends similar to those seen in other studies of attitudes and perceptions surrounding DNR orders. ${ }^{9,10}$

This study highlights the need for a structured curriculum to teach skills related to end-of-life issues such as DNR orders to residents in the Saudi Arabian medical system. In addition, many residents participating in this and other studies reported a general lack of confidence in issues relating to end-of-life care. ${ }^{3,9,10}$ The majority of residents surveyed believed they would benefit from additional training in conducting DNR discussions, an outcome that has been reported by others. . $^{3,910}$

\section{Conclusion}

In conclusion, an evidence-based curriculum providing instruction for improving discussions regarding DNR orders would improve physician confidence and effectiveness in caring for critically ill patients. This curriculum may include 
didactic lectures, dedicated workshops addressing DNR orders, use of standardized patients with continuous feedback, and evaluations of residents in training.

\section{Disclosure}

The authors report no conflicts of interest in this work.

\section{References}

1. Mobeireek AF, Al-Kassimi F, Al-Zahrani K, et al. Information disclosure and decision-making: the Middle East versus the Far East and the West. $J$ Med Ethics. 2008;34(4):225-229.

2. Marco CA, Bessman ES, Kelen GD. Ethical issues of cardiopulmonary resuscitation: comparison of emergency physician practices from 1995 to 2007. Acad Emerg Med. 2009;16(3):270-273.

3. Siddiqui MF, Holley JL. Residents' practices and perceptions about do not resuscitate orders and pronouncing death: an opportunity for clinical training. Am J Hosp Palliat Care. 2011;28(2):94-97.

4. Gouda A, Al-Jabbary A, Fong L. Compliance with DNR policy in a tertiary care center in Saudi Arabia. Intensive Care Med. 2010;36(12): 2149-2153.

5. Sha'ban Fatwas [Fatwa 12086, Part 25, pages 81-82]. The General Presidency of Scholarly Research and Ifta. Riyadh, Kingdom of Saudi Arabia. Available from http://alifta.com/Search/ResultDetails.aspx?lang= en $\&$ view $=$ result $\&$ fatwaNum $=\&$ FatwaNumID $=\& I D=9766 \&$ search Scope $=7 \&$ SearchScopeLevels $1=\&$ SearchScopeLevels $2=\&$ highLight $=$ $1 \&$ SearchType $=$ exact $\&$ SearchMoesar $=$ false $\&$ bookID $=\&$ LeftVal $=0 \&$ Right $\mathrm{Val}=0 \&$ simple $=\&$ SearchCriteria $=$ allwords $\&$ PagePath $=\&$ siteSection $=$ $1 \&$ searchkeyword $=049050048056054 \#$ firstKeyWordFound. Accessed May 18, 2015. Arabic.

6. Al-Hazzaa HM. Prevalence of physical inactivity in Saudi Arabia: a brief review. East Mediterr Health J. 2004;10(4-5):663-670.

7. Samarkandi A. Medico-legal liabilities of anesthesia practice in Saudi Arabia. Middle East J Anaesthesiol. 2006;18(4):693-706.
8. Sulmasy DP, Sood JR, Ury WA. Physicians' confidence in discussing do not resuscitate orders with patients and surrogates. $J$ Med Ethics. 2008;34(2):96-101.

9. Deep KS, Green SF, Griffith CH, Wilson JF. Medial residents' perspectives on discussions of advanced directives: can prior experience affect how they approach patients? J Palliat Med. 2007;10(3):712-720.

10. Dunlay SM, Foxen JL, Cole T, et al. A survey of clinician attitudes and self-reported practices regarding end-of-life care in heart failure. Palliat Med. 2015;18(3):217-224.

11. Morrison RS, Morrison EW, Glickman DF. Physician reluctance to discuss advance directives. An empiric investigation of potential barriers. Arch Intern Med. 1994;154(20):2311-2318.

12. Senaratne DN, Gosney MA. Do not attempt cardiopulmonary resuscitation documentation: do doctors respond to national changes? Resuscitation. 2015;87:e9.

13. Stevens A, Hernandez J, Johnsen K, et al. The use of virtual patients to teach medical students history taking and communication skills. $\mathrm{Am}$ J Surg. 2006;191(6):806-811.

14. Tang ST, Liu TW, Liu LN, Chiu CF, Hsieh RK, Tsai CM. Physicianpatient end-of-life care discussions: correlates and associations with end-of-life care preferences of cancer patients - a cross-sectional survey study. Palliat Med. 2014;28(10):1222-1230.

15. Cohn S, Fritz ZB, Frankau JM, Laroche CM, Fuld JP. Do not attempt cardiopulmonary resuscitation orders in acute medical settings: a qualitative study. QJM. 2013;106(2):165-177.

16. Field RA, Fritz Z, Baker A, Grove A, Perkins GD. Systematic review of interventions to improve appropriate use and outcomes associated with do-not-attempt-cardiopulmonary-resuscitation decisions. Resuscitation. 2014;85(11):1418-1431.

17. Goldrich MS. Report of the council on ethical and judicial affairs: universal out-of-hospital DNR systems, 2005. American Medical Association. Available from: http://www.ama-assn.org/go/cejareports. Accessed April 28, 2015.
Advances in Medical Education and Practice

\section{Publish your work in this journal}

Advances in Medical Education and Practice is an international, peerreviewed, open access journal that aims to present and publish research on Medical Education covering medical, dental, nursing and allied health care professional education. The journal covers undergraduate education, postgraduate training and continuing medical education

\section{Dovepress}

including emerging trends and innovative models linking education, research, and health care services. The manuscript management system is completely online and includes a very quick and fair peer-review system. Visit http://www.dovepress.com/testimonials.php to read real quotes from published authors. 